\title{
Error Analysis: A Methodological Exploration and Application
}

\section{Leigh McDowell}

\section{Nara Institute of Science and Technology (NAIST)}

\section{Reference Data:}

McDowell, L. (2020). Error analysis: A methodological exploration and application. In P. Clements A. Krause, \& R. Gentry (Eds.), Teacher efficacy, learner agency. Tokyo: JALT.

https://doi.org/10.37546/JALTPCP2019-53

Error Analysis (EA) was initially conceived in early Second Language Acquisition research in the 1960s to investigate the systems underlying learner language and has since gained wider application in English Language Teaching research. However, for many language teachers, the practical and technological barriers to employing EA in their professional practices remain restrictively high. This paper demonstrates a simple yet robust procedure for EA that can be applied by anyone with access to the commonly available tools of Microsoft Word and Excel. Additionally, by drawing on data from an EA of 18 texts written by Japanese materials scientists, the paper illustrates how this procedure can inform language teaching practices by identifying the most pressing grammatical needs within a population of L2 English users.

本来、誤答分析 (Error Analysis) は、語学学習者の言語の根本にあるシステムを調査する為に1960年代の初期第二言語習 得 (SLA) 研究中に提案されていて、その後英語教授法 (ELT) 研究に広く使われるようになった。しかし、多くの語学教師等にと

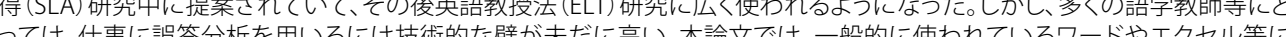

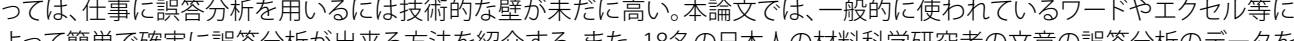

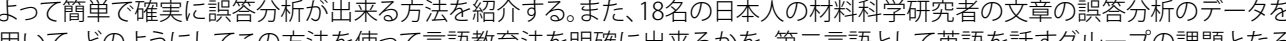
䚺浬題となる 文法の必要性を示しながらをを説明する。

rror Analysis (EA) was initially conceived in early Second Language Acquisition (SLA) research in the 1960s as a way to investigate the grammatical systems underlying learner language. Early SLA researchers viewed learner language, or what came to be known as interlanguage, as systematic with rules that approximate but differ importantly from the target language, and EA was devised to elucidate those rules (Corder, 1971; Selinker, 1972). SLA researchers distinguished between errors of performance and errors of competence, where errors of performance were simply mistakes that are not systematically repeated and therefore are easily self-corrected, while errors of competence, herein referred to simply as errors, cannot be easily self-corrected and continue to manifest until some form of pedagogical intervention, or learning is initiated. EA was a systematic approach for the examination of the various causes and ways in which errors unfold in interlanguage. To illustrate this approach, an algorithm applied in early EA studies is presented in Figure 1.

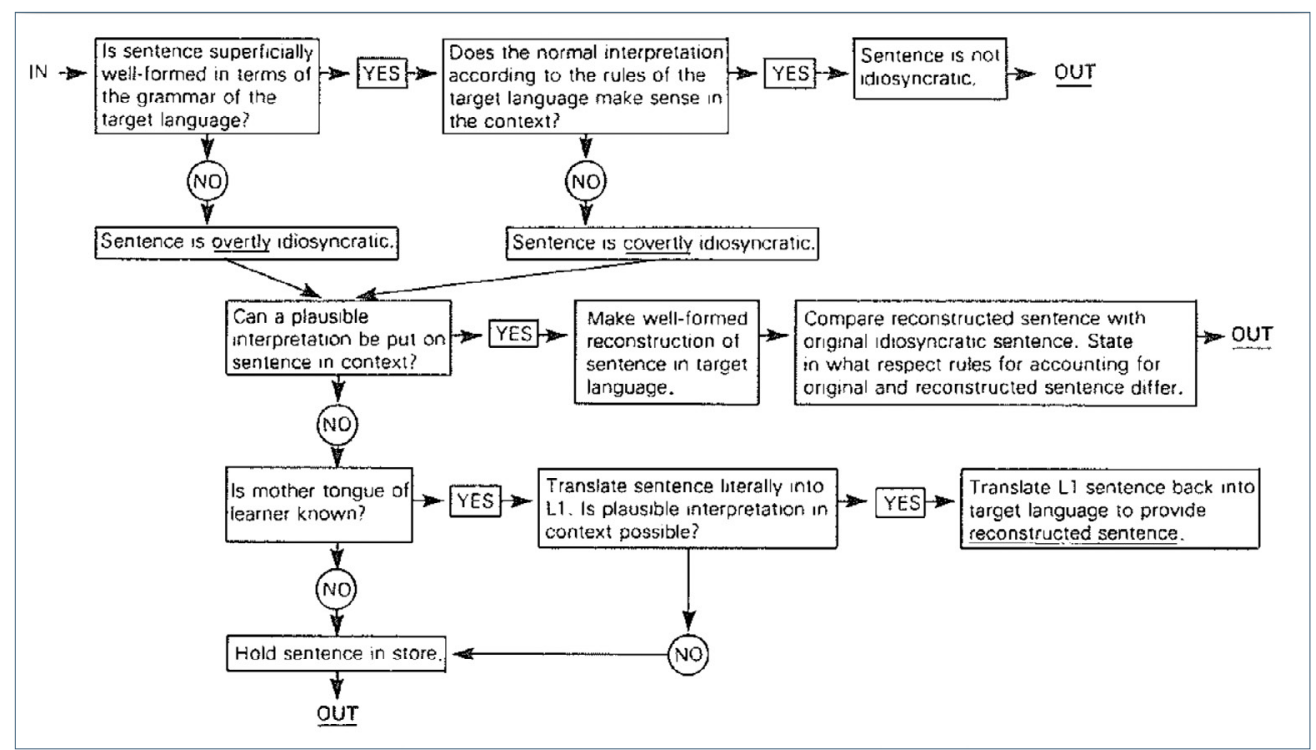

Figure 1. Algorithm for Error Analysis as originally presented by Corder (1967, pp 1-4). 
As Figure 1 illustrates, the sentence is taken as the unit of measurement, and judged for its variation from the target language, or idiosyncrasy. For example, the first step in the top left of the algorithm is to discern if the sentence is grammatically "well-formed". If it is, then the analyst follows the arrow to the right marked "yes" onto the next step, which is to judge the sentence in terms of meaning (i.e., does it make sense in context). If the analyst's judgement is "yes", then the sentence is considered "not idiosyncratic" and its analysis complete. However, if the sentence is determined as "overtly" or "covertly" idiosyncratic in terms of grammar and meaning, respectively, then the sentence progresses in the downward direction, marked "no" and on through the analysis

The method was subsequently elaborated by others (see for example, Abbott, 1980; Dulay, Burt \& Krashen, 1982; Levelt, 1978; Richards, 1974) and distinction was later drawn between inter- and intra-lingual errors, where interlingual errors involve some form of transfer from the L1, while intralingual errors do not (e.g., false hypothesis, overgeneralization, etc.; Richards, 1971), but perhaps, the most enduring legacy from this early stage of EA research was the formalization of the four principle ways in which errors unfold, herein referred to as error types (Dulay, Burt \& Krashen, 1982; James, 1998). These four error types, presented with simple examples in Table 1, are a feature of the EA procedure described in this paper.

Table 1. The Four Principle Error Types

\begin{tabular}{ll}
\hline Error Type & Example \\
\hline Omission & $\underline{\text { the sample }}$ \\
Addition & the thermoelectric materials \\
Selection & limited for to previously-known samples \\
Ordering & this method can also be also-applied \\
\hline
\end{tabular}

Note: Red underline and strikethrough text indicates the error.

In the omission error example, the red underline text indicates that the definite article the was originally omitted and later "reconstructed" by the analyst. For the addition error example, the was added incongruently and later deleted by the analyst, as indicated by the red strikethrough text. The selection error example shows the preposition for was mis-selected for to, and in the ordering error example also was relocated by the analyst to improve syntax. Surprisingly, these four error types can be applied to describe almost all sentence-level grammar errors.
In SLA research, EA was mostly abandoned by the 1990s for various reasons, including the avoidance argument (i.e., learners' avoidance of certain forms cannot be accounted for by EA; Schachter \& Celce-Murcia, 1977) and the comparative fallacy hypothesis (i.e., the true character of interlanguage is obscured by adherence to L1 forms; Bley-Vroman, 1983). After it became apparent that EA could not account for the full complexity and psychology behind interlanguage, SLA researchers turned towards cognitive linguistics, psycholinguistics, and sociocultural approaches, to advance their investigations and further develop theory. However, EA has always had a more practical application in English Language Teaching (ELT) as a way of tackling the perennial issue of accuracy. While a detailed review of the applications of EA in ELT is beyond the scope of this paper, one notable project is the International Corpus of Learner English (ICLE; Granger, 2003). The ICLE project integrated EA with a corpus linguistics approach to examine error patterning across large populations from particular L1 backgrounds; for example, L1 Spanish-speakers of English, L1 German-speakers of English, etc. The outcomes of this project include not only deep pedagogical insights into stereo-typical error patterning within specific L1 backgrounds, but also a suite of digital tools that can be utilized for EA, including an electronic error tagger, concordancer and frequency analysis tools (Figure 2).
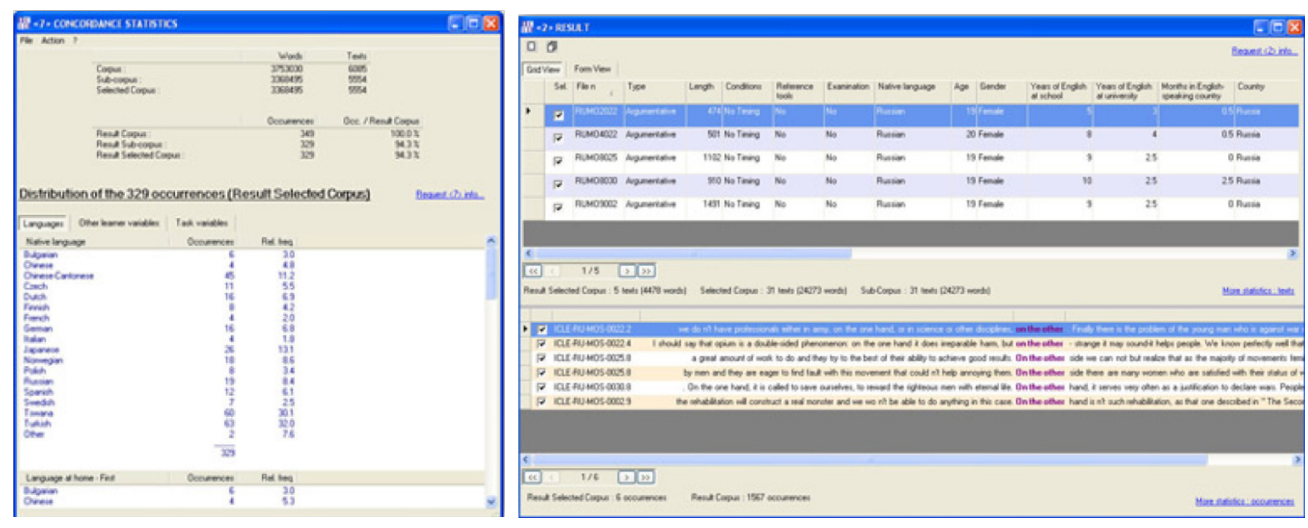

Figure 2. Screenshots of the International Corpus of Learner English (ICLE) concordancer and frequency analysis tool (Granger, 2003).

While the ICLE resources have served researchers well and helped update EA into the information age, there are problems for the average language teacher in applying them in everyday language teaching contexts, not least of all the high price tag. At the time 
of writing this paper, the ICLE suite cost 225 Euros for a single-user license. This price may be on par with other software packages, for example Microsoft Office, but users are effectively paying for software that is already well out of date-the original release date of the ICLE package was 2002 and the last update was more than ten years ago in 2009. Add to this the cost of the time required to learn how to use the outdated interface, and the practical value may be beyond the means of the average teacher/researcher. Thus, there remains to date no standard or viable option for teachers wanting to apply EA in their everyday contexts.

To address this gap, this paper presents a simple yet robust electronic procedure for EA that requires only the commonly available tools of Microsoft Word and Excel Additionally, it demonstrates an application of the procedure with an error analysis of 18 texts, illustrating how it can inform language teaching practices by identifying the most pressing grammatical needs of L2 English users.

\section{Procedure for Error Analysis}

The EA procedure described in this section is outlined in four distinct stages: (1) proofreading, (2) coding, (3) quantification, and (4) sorting.

\section{Proofreading}

This initial proofreading stage is essentially the identification and correction of errors in a written text. This procedure utilizes Microsoft Word and its Track Changes function to markup errors, as illustrated in Figure 3.

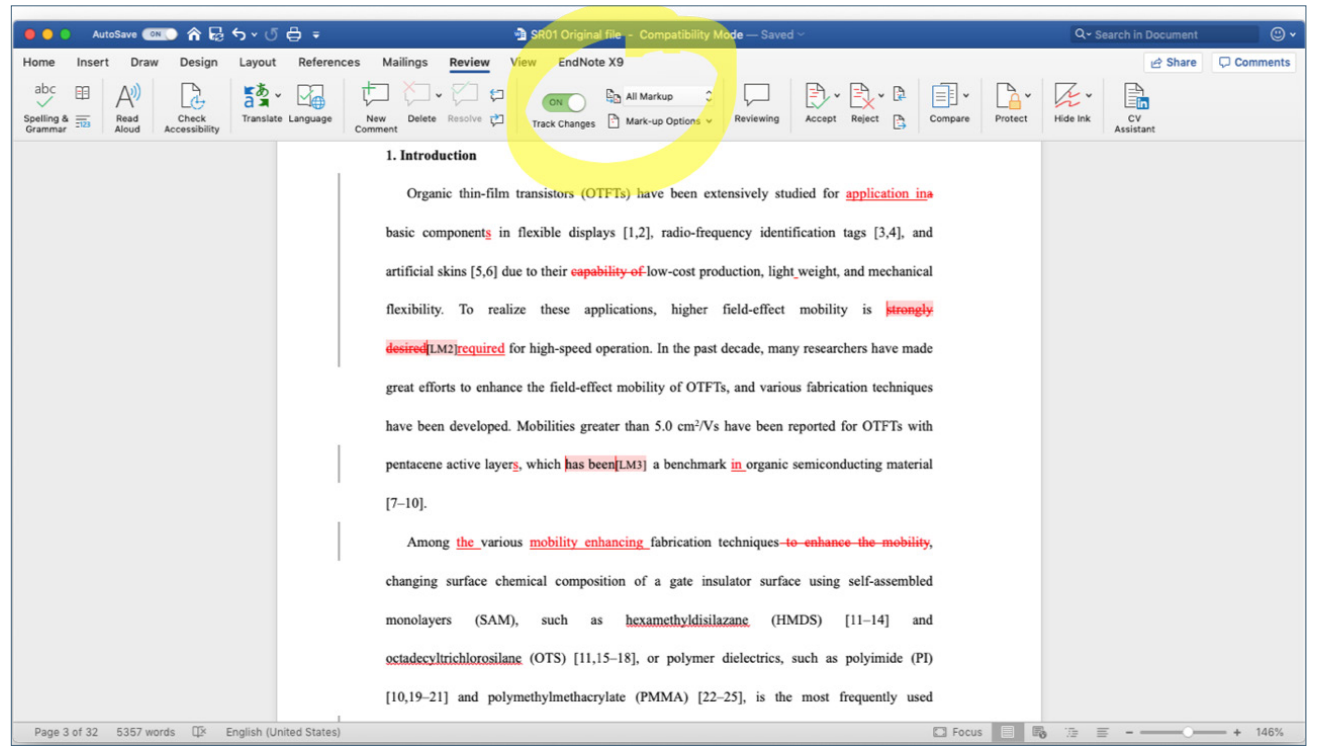

Figure 3. Example text illustrating the proofreading stage with error markup using the Microsoft Word Track Changes function.

Errors are identified as idiosyncratic language differing from the target language and reconstructed to grammatical form (Corder, 1971). With the Track Changes function turned on (highlighted with a yellow circle in Figure 3), the reconstructions that the analyst applies to a text are annotated with color-coded strikethrough for deletions, and underline for additions. This use of the Track Changes function is advantageous not only because of its common use in ELT-many teachers will already have doc or docx files with this form of error annotation in place-but also because of its compatibility with Microsoft Excel, which is utilized in the subsequent coding, quantification, and sorting stages described below.

\section{Coding}

After errors have been identified in context and marked up, the Track Changes function is turned off and the sentences containing errors are copy-pasted over to an Excel spreadsheet for coding, with the error annotation remaining intact, as illustrated in Figure 4. 


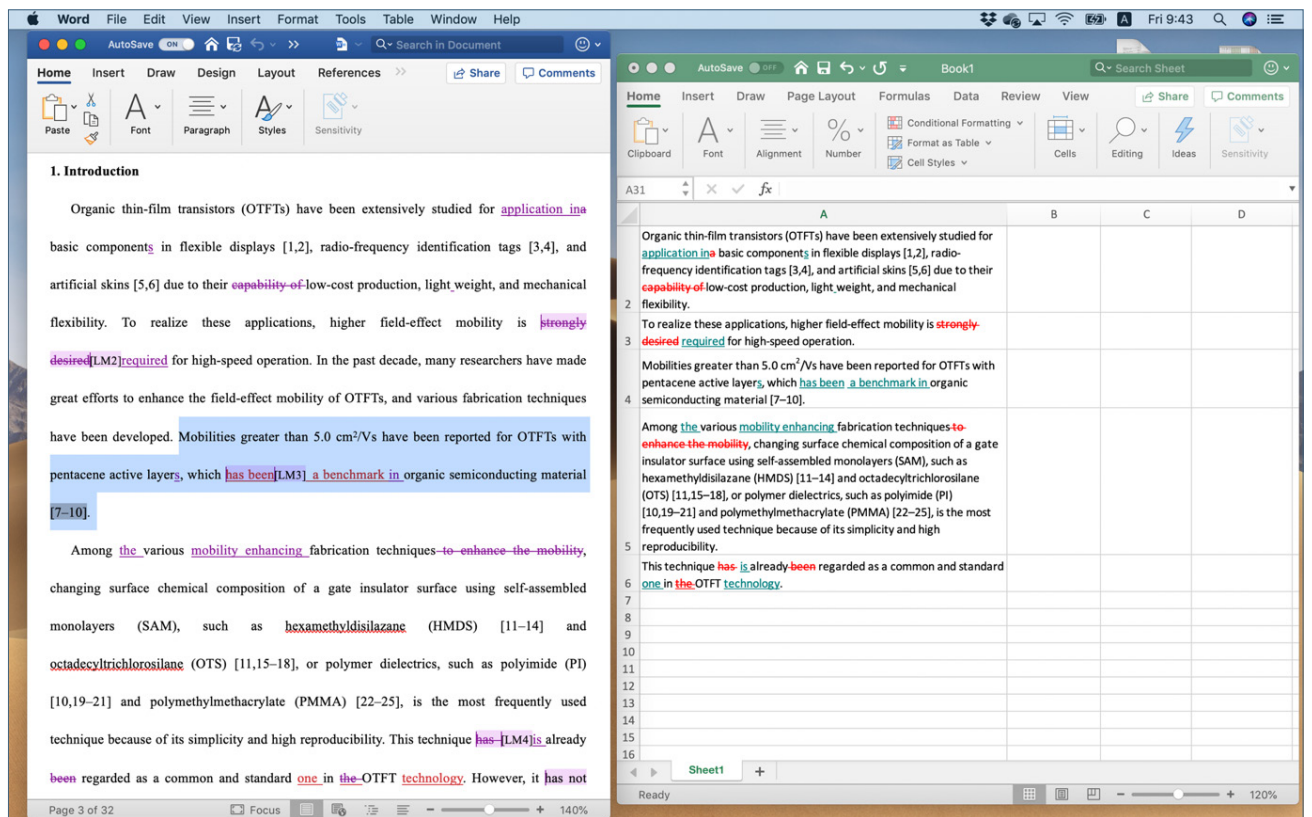

Figure 4. Screenshot illustrating the copy-pasting of sentences with errors marked-up from Microsoft Word doc to Excel sheet.

As described earlier in the Background section, the sentence is taken as the unit of measurement. Alternatives include the T-unit and clause (Wolfe-Quintero, Inagaki, \& $\mathrm{Kim}, 1998$ ): however, the sentence presents itself as the most easily and consistently identifiable unit because of its well-defined written boundary in the full-stop. Once all sentences with errors are copied over to an Excel sheet, three columns are created for (1) error type, (2) error, and (3) reconstruction, as illustrated in Figure 5.

\begin{tabular}{|c|c|c|c|c|c|c|c|c|c|c|}
\hline & ime insert & Draw Page Layout Formulas & Dats Revii & ew View & & & & share & Dcommer & \\
\hline & Citce & 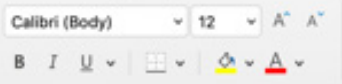 & 厗. & $\begin{array}{c}\% \text {. } \\
\text { Number }\end{array}$ & 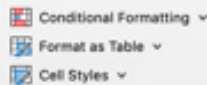 & 画。 & O. & $\sum_{1000}^{3}$ & Sersitiont & \\
\hline 81 & $\forall x$ & $\checkmark f_{x}$ & & & & & & & & \\
\hline 2 & & A & & & B & c & & D & & \\
\hline 1 & Sentence & & & & Error type & Error & $\operatorname{Rec}$ & onstructi & & \\
\hline 2 & $\begin{array}{l}\text { Organic th } \\
\text { for applica } \\
\text { frequency } \\
\text { their capal } \\
\text { flexibility. }\end{array}$ & $\begin{array}{l}\text { in-film transistors (OTFTs) have been } \\
\text { tion ina basic components in flexible } \\
\text { identification tags [3,4], and artificial } \\
\text { bility-oflow-cost production, light we }\end{array}$ & $\begin{array}{l}\text { extensivel } \\
\text { displays [1 } \\
\text { skins }[5,6] \\
\text { ight, and } m\end{array}$ & $\begin{array}{l}\text { y studied } \\
\text { 2], radio- } \\
\text { due to } \\
\text { eechanical }\end{array}$ & omission & & $0 \mathrm{appl}$ & lication in & & \\
\hline 3 & $\begin{array}{l}\text { Organic thi } \\
\text { for applica } \\
\text { frequency } \\
\text { their capat } \\
\text { flexibility. }\end{array}$ & $\begin{array}{l}\text { in-film transistors (OTFTs) have been } \\
\text { tion ina basic components in flexible } \\
\text { identification tags }[3,4] \text {, and artificial } \\
\text { bility-oflow-cost production, light we }\end{array}$ & $\begin{array}{l}\text { extensivel } \\
\text { displays [1 } \\
\text { skins }[5,6] \\
\text { ight, and } m\end{array}$ & $\begin{array}{l}\text { y studied } \\
\text { 2], radio- } \\
\text { due to } \\
\text { eechanical }\end{array}$ & addition & a & & & 0 & \\
\hline 4 & $\begin{array}{l}\text { Organic thi } \\
\text { for applicat } \\
\text { frequency } \\
\text { their capat } \\
\text { flexibility. }\end{array}$ & $\begin{array}{l}\text { in-film transistors (OTFTs) have been } \\
\text { tion ina basic components in flexible } \\
\text { identification tags }[3,4] \text {, and artificial } \\
\text { bility-oflow-cost production, light we }\end{array}$ & $\begin{array}{l}\text { extensivel } \\
\text { displays [1 } \\
\text { skins }[5,6] \\
\text { ight, and } m\end{array}$ & $\begin{array}{l}\text { y studied } \\
\text { 2], radio- } \\
\text { due to } \\
\text { nechanical }\end{array}$ & selection & component & & nponents & & \\
\hline 5 & $\begin{array}{l}\text { Organic thi } \\
\text { for applicat } \\
\text { frequency } \\
\text { their capab } \\
\text { flexibility. }\end{array}$ & $\begin{array}{l}\text { in-film transistors (OTFTs) have been } \\
\text { tion ina basic components in flexible } \\
\text { identification tags }[3,4] \text {, and artificial } \\
\text { bility of low-cost production, light we }\end{array}$ & $\begin{array}{l}\text { extensivel } \\
\text { displays [1 } \\
\text { skins }[5,6] \\
\text { light, and } m\end{array}$ & $\begin{array}{l}\text { y studied } \\
\text { 2], radio- } \\
\text { due to } \\
\text { echanical }\end{array}$ & addition & capability of & & & 0 & \\
\hline & $\begin{array}{l}\text { To realize t } \\
\text { desired rea } \\
\text { sheett }\end{array}$ & $\begin{array}{l}\text { hese applications, higher field-effect } \\
\text { uired for high-speed operation. }\end{array}$ & mobility is & strengly & & & & & & \\
\hline & eady & & & & & & & & & \\
\hline
\end{tabular}

Figure 5. Screenshot of Excel sheet illustrating error coding.

As shown in Figure 5 column B, the error type is coded according to the four principle error types presented earlier (i.e., omission, addition, selection, and ordering). In column $\mathrm{C}$, the error is coded by the words or morphemes that are omitted, added, mis-selected, or mis-ordered, and in column $\mathrm{D}$, the reconstruction is the correction of the error to its grammatical form. For example, the first error in row 2 is the omission of the phrase "application in", so the error type is coded as omission, the error is "0", or zerorepresenting nothing there initially - and the reconstruction is "application in" (i.e., omission, 0, application in). Similarly, in row 3 the error is the incongruent addition of an 
McDowell: Error Analysis: A Methodological Exploration and Application

indefinite article, so the error type is addition, the error is "a", and the reconstruction is zero (i.e., addition, $a, 0$ ). And in row 4 , the singular form of "component" is mis-selected for plural form (i.e., selection, component, components), and so on.

Note that sentences will often contain multiple errors. When this occurs, the sentence is duplicated to a separate row, and individual errors analyzed separately, as shown in Figure 5. Once all errors are coded according to the three parameters, this stage is complete, and the analysis moves to quantification.

\section{Quantification}

The quantification stage utilizes Excel's countifs formula to tally up, or quantify error frequencies. Firstly, as Figure 6 demonstrates, a new column is created titled Frequency, and the following formula inserted.

$=$ countifs $(C: C, C 2, D: D, D 2, E: E, E 2)$

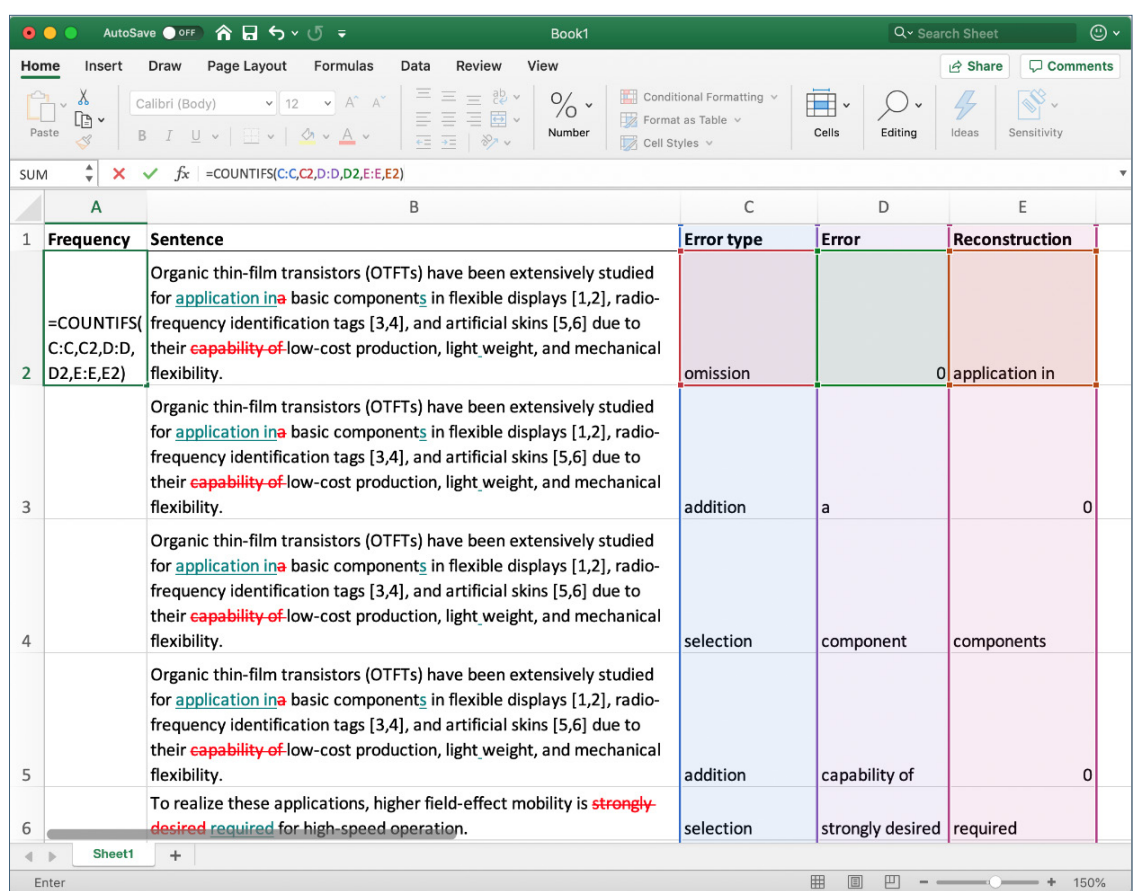

Figure 6. Screenshot demonstrating the quantification stage using the Excel countifs formula.
This formula effectively counts the number of times (i.e., frequency) a specific error pattern occurs. For example, in row 2 of Figure 6, the formula counts the number of times that the error type, "omission" occurs in column C, and subsequently the error,

"0", or zero in column D, and the reconstruction, "application in" in column E (i.e., omission, 0, application in). By copy-pasting this formula down the column, the resultant frequencies reveal commonly occurring error patterns, as shown in Figure 7.

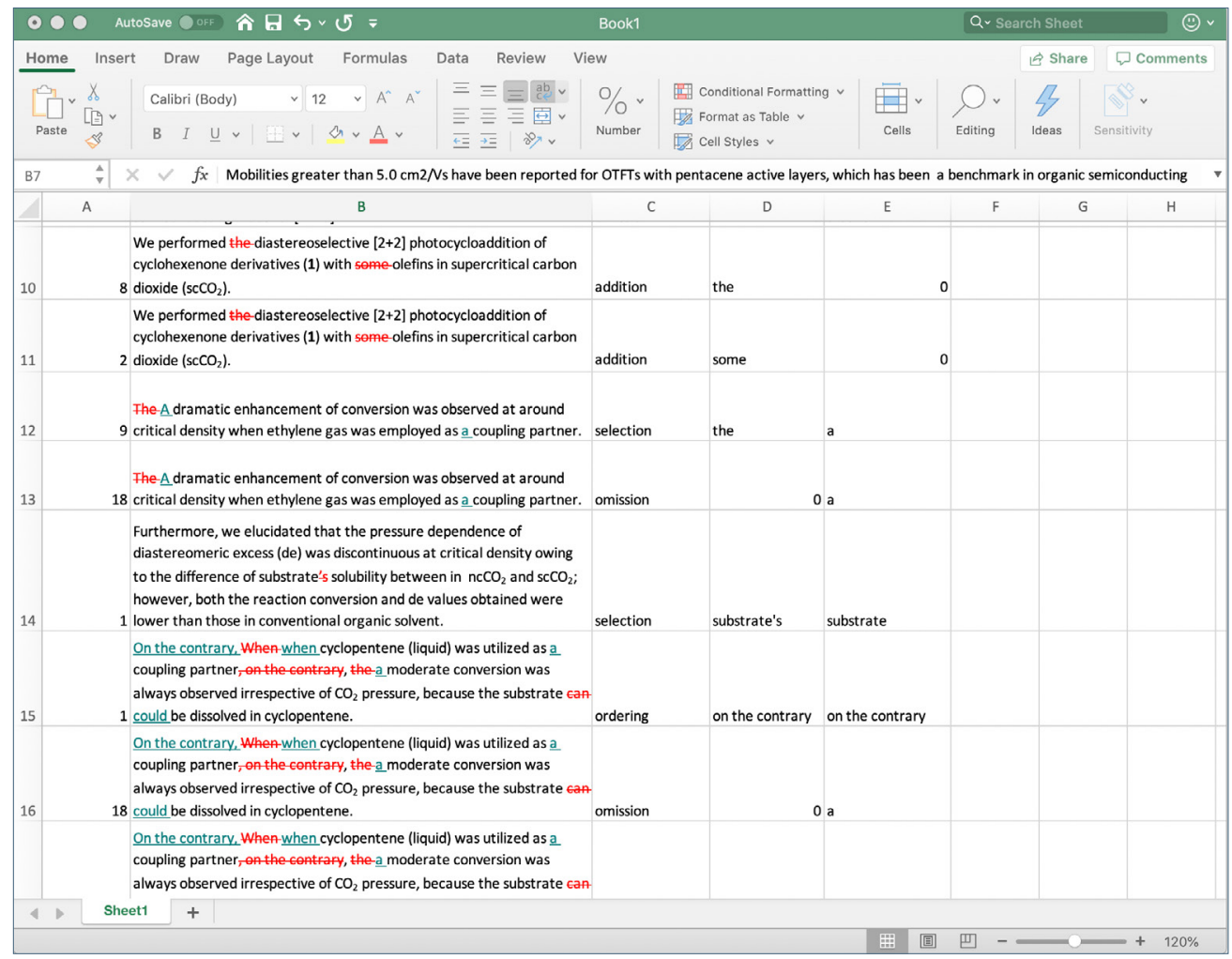

Figure 7. Screenshot illustrating errors with frequencies quantified in the far-left column.

Column A in Figure 7 shows several error patterns occurring with multiple frequency; for example, there are eight occurrences of (addition, the, 0 ), nine occurrences of (selection, the, $a$ ) and 18 occurrences of (omission, $0, a$ ). The next stage sorts these frequencies for ease of identification. 


\section{Sorting}

The fourth and final stage of this procedure applies the Excel sort function to sort error frequencies from largest to smallest, facilitating easy identification of the most frequent error patterns. To do this, from the Data menu, select Sort, and sort on column A, or Frequency, from Largest to Smallest, as illustrated in Figure 8.

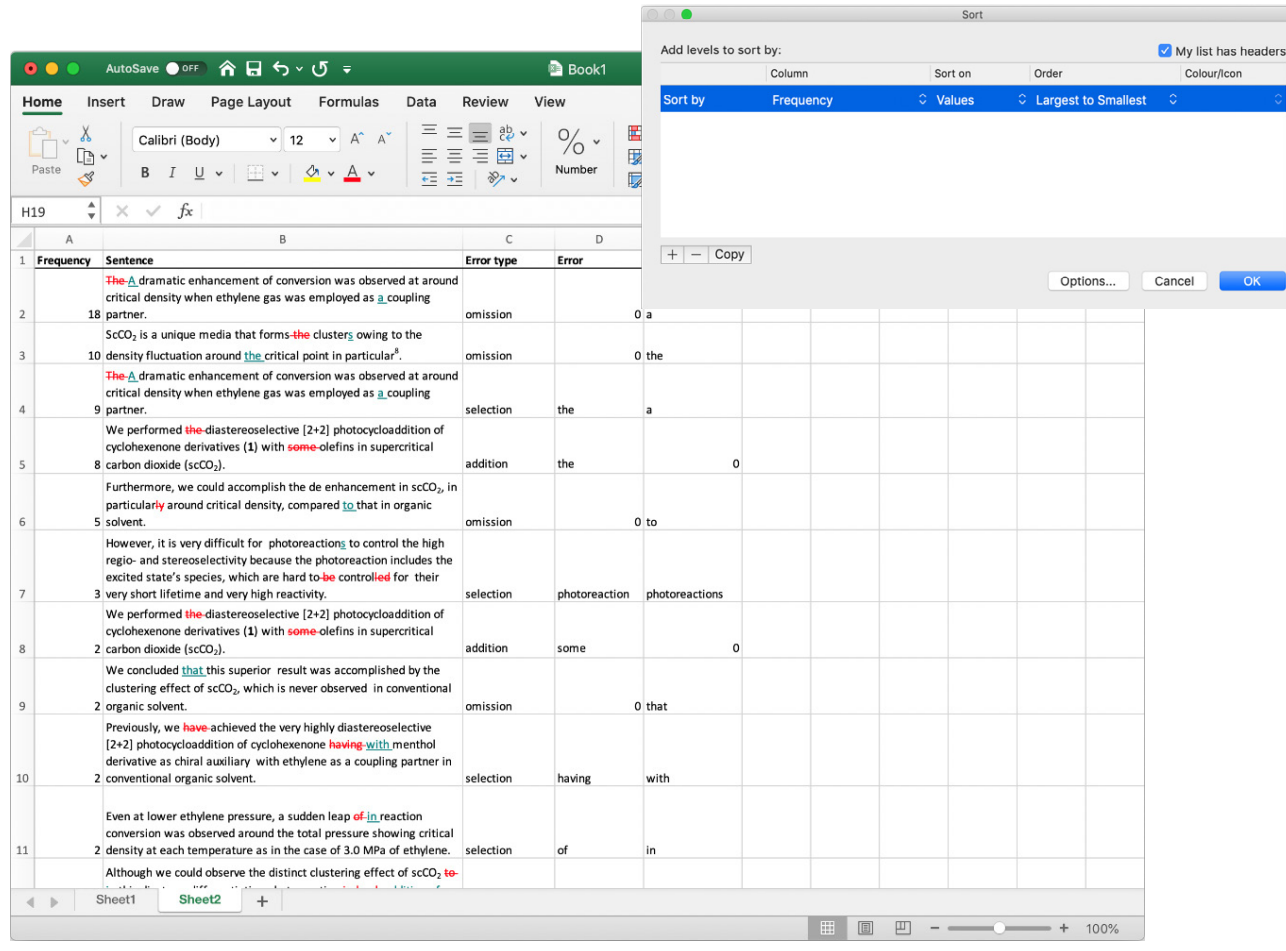

Figure 8 . Sorting error patterns by frequency to identify most frequent error patterns.

Figure 8 presents a new sheet (i.e., Sheet2) with one sample error from each error pattern, and clearly outlines the most frequent error patterns in this analysis: the omission of the indefinite article, occurring 18 times; the second most frequent pattern, the omission of the definite article, occurring ten times; the third, the mis-selection of "the" for "a", occurring nine times, and so on. Presented in this way, the most frequently occurring error patterns and subsequently the most pressing grammar needs are immediately apparent.

This concludes the description of the procedure, but before moving on to a demonstration of its application, it bears noting that while it was presented with screenshots from a Mac computer, the procedure is equally applicable for Windows machines, since Microsoft Word and Excel function almost completely the same in both environments. Furthermore and importantly, the analysis demonstrated above was for a single text, but where EA becomes even more insightful is in the investigation of error patterning across multiple texts, or within a population, for example a class of language learners, or as in the case of the following analysis, the research writing of Japanese materials scientists.

\section{Application of Error Analysis Procedure}

This section demonstrates an application of the above procedure with a small-scale EA of texts written by Japanese materials scientists. In materials science, as in most of the physical sciences, English is commonly employed as the lingua franca of research publication, and Japanese materials scientists have reported, not only the centrality of English in their professional lives, but also the importance of accuracy in their research writing and the challenges that ensue in trying to achieve such accuracy (McDowell \& Liardét, 2019). As such, an EA outlining common or frequent error patterns would be of benefit to this population.

The texts analyzed in this EA are research articles, in which the need for accuracy and precision is imperative. Consent was requested from and granted by 18 Japanese materials scientists to collect and analyze one of their research article manuscripts each, for a total of 18 texts. A manuscript, as it is referred to in this study, is the text before publication but after copyediting, with errors intact, which have been identified and reconstructed by a professional copyeditor. The EA was conducted following the procedure described above. An overview of the corpus with initial descriptive statistics is presented in Table 2. 
Table 2. Overview of 18-Text Corpus and Errors

\begin{tabular}{|c|c|c|c|c|c|c|c|c|c|}
\hline$\stackrel{\vec{x}}{\stackrel{u}{\oplus}}$ & $\begin{array}{l}0 \\
0 \\
3 \\
3\end{array}$ & 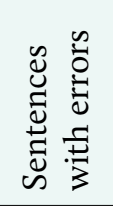 & 芯 & 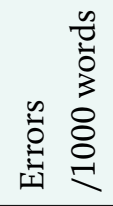 & 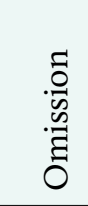 & 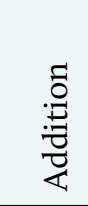 & 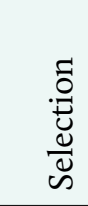 & 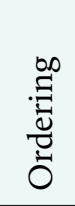 & $\frac{\bar{\Xi}}{\overline{0}}$ \\
\hline JR01 & 3,283 & 7 & 9 & 3 & 2 & 0 & 7 & 0 & 0 \\
\hline JR02 & 3,453 & 21 & 31 & 9 & 3 & 11 & 14 & 2 & 1 \\
\hline JR03 & 4,115 & 34 & 40 & 10 & 8 & 8 & 19 & 4 & 1 \\
\hline JR04 & 2,651 & 17 & 29 & 11 & 11 & 1 & 16 & 1 & 0 \\
\hline JR05 & 2,056 & 23 & 35 & 17 & 13 & 11 & 11 & 0 & 0 \\
\hline JR06 & 3,065 & 51 & 84 & 27 & 19 & 28 & 25 & 12 & 0 \\
\hline JR07 & 4,175 & 43 & 72 & 17 & 22 & 24 & 22 & 1 & 3 \\
\hline JR08 & 3,210 & 60 & 99 & 31 & 26 & 30 & 34 & 5 & 4 \\
\hline JR09 & 1,824 & 43 & 89 & 49 & 22 & 14 & 48 & 2 & 3 \\
\hline SR03 & 2,630 & 70 & 149 & 57 & 42 & 18 & 79 & 10 & 0 \\
\hline SR05 & 4,157 & 26 & 32 & 8 & 7 & 7 & 16 & 2 & 0 \\
\hline SR10 & 2,164 & 35 & 84 & 39 & 19 & 19 & 45 & 1 & 0 \\
\hline SR11 & 1,598 & 38 & 61 & 38 & 21 & 9 & 25 & 1 & 5 \\
\hline SR12 & 3,821 & 18 & 20 & 5 & 3 & 4 & 11 & 2 & 0 \\
\hline SR13 & 4,415 & 97 & 173 & 39 & 43 & 34 & 91 & 5 & 0 \\
\hline SR15 & 966 & 16 & 25 & 26 & 6 & 4 & 13 & 2 & 0 \\
\hline SR26 & 5,514 & 66 & 118 & 21 & 23 & 26 & 68 & 1 & 0 \\
\hline SR29 & 3,900 & 66 & 109 & 28 & 40 & 12 & 52 & 3 & 2 \\
\hline Totals & 56,997 & 731 & 1,259 & 22 & 330 & 260 & 596 & 54 & 19 \\
\hline Mean & 3,167 & 41 & 70 & & 18 & 14 & 33 & 3 & 1 \\
\hline Min & 966 & 7 & 9 & 3 & 2 & 0 & 7 & 0 & 0 \\
\hline Max & 5,514 & 97 & 173 & 57 & 43 & 34 & 91 & 12 & 5 \\
\hline
\end{tabular}

As outlined in Table 2, the corpus comprises 18 texts, 56,977 words, and a total of 1,259 errors. When normalized, the texts include on average 22 errors per 1,000 words. Put in perspective, this means an average single-spaced A4 page of around 500 words would contain around 11 grammatical errors, which is probably a level of imprecision that most researchers would be uncomfortable with, and evidence of the difficulties Japanese materials scientists face in using English for professional purposes. The breakdown of error types in Table 2 highlights selection errors as the predominant error type, followed by omission, then addition, and relatively few ordering errors. However, it is more important to know exactly what is being omitted, added, or mis-selected. For this level of analysis, Table 3 presents the top-ten most frequent error patterns within the corpus.

Table 3. Most Frequent Errors

\begin{tabular}{|c|c|c|c|c|c|c|}
\hline $\begin{array}{l}\text { בै } \\
\text { ๘ }\end{array}$ & 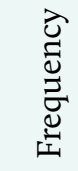 & 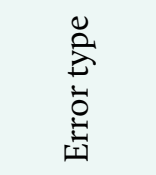 & 它 & 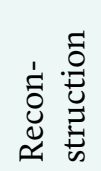 & 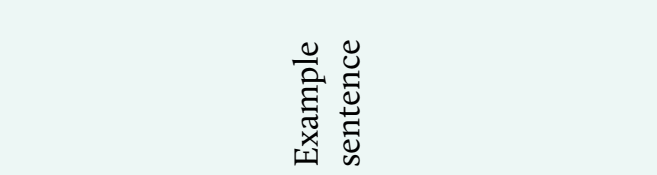 & 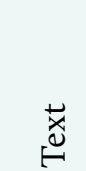 \\
\hline 1 & 124 & omission & $\varnothing$ & the & $\begin{array}{l}\text { The - Ponaindomain-swapped dimer of } \\
\text { holoMb has been reported to be more stable } \\
\text { than that of apoMb. }\end{array}$ & JR02 \\
\hline
\end{tabular}

286 addition the $\varnothing \quad$ Cyt b562 from E. coli is a relatively small (MW: 12,000) heme protein responsible for the electron transfer in the periplasm.

374 omission $\varnothing \quad$ a $\quad$ The decrease in the amount of oligomers containing the apo protein may result in $\underline{a}$ decrease in formation of domain-swapped oligomers.

$4 \quad 47$ addition of $\varnothing \quad$ This equilibrium is considered to take place JR07 both on the side and tip faces, whereas the ligand desorption-of ligand could be predominant at the tips with the weaker affinity to thiolate ligands than the side face,1,31 leading an uncapped hydrophobic face. 


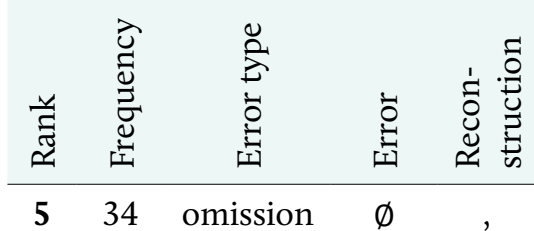

Among various types of NC-assemblies, $1 \mathrm{D}$ assemblies are of particular interest due to their vectorial properties, such as directional carrier transport and energy transfer properties.

626 selection the a Under the slug flow condition, they reported the a higher efficiency of photooxygenation than that under the oxygen bubble flow condition.

717 omission $\varnothing \quad$ an Actually, an obvious difference in results was obtained for each solvent.

815 selection of in The chemical shift perturbations of $\underline{\text { in }}$ the cyt $c$ backbone $\mathrm{NH}$ signals by interaction with bicelles were observed, owing to the small bicelle size and weak interaction with a limited number of CL in each bicelle.

914 omission $\varnothing \quad$ - $\quad$ Recent progress in the high high-yield synthesis of SWNTs relies on a long catalyst lifetime in the chemical vapour deposition, leading to the production of SWNTs with large diameters $(>\sim 1.5 \mathrm{~nm})$ and lengths of tens of mm.

1014 selection were was Actually, an obvious difference in results were was obtained for each solvent.

As can be seen in Table 3, five of the ten most frequent errors concern articles; specifically, the omission of the, addition of the, omission of $a$, selection of the for $a$, and omission of an. For many involved in ELT in Japan, these results would confirm the wellknown difficulties Japanese people experience with the English article system. While a deep discussion on these errors is beyond the scope of this paper (for a detailed treatment see McDowell, 2016; McDowell \& Liardet, 2020), it can be said here that any pedagogy aimed at supporting Japanese materials scientists in their use of English, and possibly other Japanese scientists, would need to address this area of the grammar. Similarly, Table 3 highlights the preposition of as problematic: of-addition is the fourth most frequent error, occurring 47 times, and of-selection for in is eighth, with 15 occurrences. Again, this result will resonate with ELT professionals in Japan, who would notice the tendency for Japanese to overuse preposition of as a typical way to build noun phrases.

Other frequent error patterns involve punctuation: the fifth ranked error is the omission of the comma, and the eighth is the omission of the hyphen. In research writing, the omission of commas creates difficulties for readers trying to parse the dense and complicated language, and in some cases, may even affect meaning (e.g. distinguishing restrictive from non-restrictive sub-clauses). Similarly, hyphens are often needed in research writing to distinguish meaning in novel noun phrases; for example, there is an important difference between a first-time traveler, and a first time-traveler. Finally, the tenth ranked error is the mis-selection of were for was, indicating that subject-verb agreement remains an issue for Japanese materials scientists.

\section{Discussion}

Naturally, after error patterns have been identified, they become targets for pedagogical treatment. With this data-driven approach, the language teacher is provided with not only the specific error patterns, but also a host of sample texts and sentences that can be applied to develop specialized learning resources. As an example, the Appendix demonstrates a set of learning exercises developed specifically from the EA data in this study to help Japanese materials scientists learn from their most frequent error pattern: errors with articles. The exercises presented in the Appendix follow best practices gleaned from the literature on written corrective feedback in that they are both "focused" and "indirect" (Ferris, Liu, Sinha \& Senna, 2013). Focused in this context means that correction is focused on a specific error pattern based on learners' needs, and indirect means that the errors are firstly highlighted (i.e., underlined) but not directly corrected, giving learners the opportunity for reflection. After learners have had the opportunity to process and correct the errors themselves, teachers can then point to better language choices in the given context. The error reconstructions for the exercises are given in the answer sections. How teachers choose to present them and address the grammar pedagogically will differ according to individual approaches, but Ferris, et al. (2013) highlight that explicit instruction benefits L2 learners familiar with formal grammar instruction (p. 309). 
In terms of limitations, while the analysis presented here enables the pinpointing of specific errors, it may overlook errors involving low-frequency content words; for example, the mis-selection of singular for plural forms (e.g., component/components), or subject-verb agreement errors (e.g., analyze/analyzes). A solution to this issue is to extend the analysis to include parts-of-speech (POS). For example, TagAnt (Anthony, 2015), a freely available online POS tagger, can be utilized to code both the error and reconstruction, and the same procedure applied as above to quantify and sort error patterns by POS. This wider-angle view could reveal error patterns otherwise overlooked by the above described analysis.

Furthermore, the analysis of multiple texts is a time-demanding task that may be beyond the time-constraints of typical teachers. As such, its applicability may be limited to those with time to dedicate towards research activities and whose teaching context emphasizes the importance of accuracy. It follows then that if a teacher or researcher goes to the trouble of assembling and analyzing a corpus for errors using this procedure, they may consider taking their efforts a step further and developing specialized automated error detection. While this is beyond the scope of this paper, future work with this error analysis procedure may include its application in the development of automatic error detection resources.

Finally, in this discussion it is prudent to note that not all that can be counted counts, and not all that counts can be counted (a maxim often ascribed to Albert Einstein, but first recorded in Cameron, 1963). That is to say that this procedure enables the elucidation of error patterns but accounts for none of the weighting, or impact of those errors. Further investigations applying this procedure would do well to examine errors in terms of acceptability. Certain errors will be more critical than others, and some may have little impact on comprehensibility initially but confusion may build with frequency. By ascertaining responses to certain errors, a clearer picture could be drawn of their impact. Similarly, gauging responses to the buildup of errors in a text-for example 10 errors per 1,000 words versus 20 errors per 1,000 words, versus 30, and so on-may help us understand how they compound with each other to undermine comprehensibility. These are issues that it is hoped can be investigated more carefully with the application of the procedure described in this paper.

\section{Conclusion}

This paper has presented a simple yet robust procedure for error analysis that can be applied by ELT professionals in their everyday teaching contexts to elucidate frequently occurring error patterns in a single text or across multiple texts representing a population (e.g., a class of language learners). Additionally, it has presented an application of the procedure with an error analysis of research articles written by Japanese materials scientists, outlining their ten most frequently occurring errors.

\section{Bio Data}

Leigh McDowell is an Associate Professor at the Nara Institute of Science and Technology (NAIST) in Japan, where he teaches research writing, academic presentation and discussion skills, and professional communication to graduate students. His research interests include English for Specific Purposes (ESP), English for Research Publication Purposes (ERPP), Systemic Functional Linguistics (SFL), and Corpus Linguistics. He lives in the beautiful prefecture of Nara, where he is an active member of the local Nara JALT chapter. <leigh-mcdowell@ms.naist.jp>

\section{Acknowledgement}

Thanks to the 18 Japanese materials scientists who consented to use of their research article manuscripts for this study, and to Dr. Robb King from the Nara Institute of Science and Technology for translation support. Also, thanks to the anonymous reviewers for constructive feedback, and content editor, Chris Cooper, for his careful and efficient support in manuscript preparation.

\section{References}

Abbott, G. (1980). Towards a more rigorous analysis of foreign language errors. International Review of Applied Linguistics in Language Teaching, 18(1-4), 121-134. https://doi.org/10.1515/ iral.1980.18.1-4.121

Anthony, L. (2015). TagAnt (Version 1.2.0). Tokyo: Waseda University. Retrieved from http://www. laurenceanthony.net/software/tagant/.

Bley-Vroman, R. (1983). The comparative fallacy in interlanguage studies: The case of systematicity. Language Learning, 33(1), 1-17. https://doi.org/10.1111/j.1467-1770.1983.tb00983

Cameron, W. B. (1963). Informal sociology: A casual introduction to sociological thinking (Vol. 21). New York: Random House.

Corder, S. P. (1967). The significance of learner's errors. International Review of Applied Linguistics in Language Teaching, 5(1-4), 161-170. https://doi.org/10.1515/iral.1967.5.1-4.161

Corder, S. P. (1971). Idiosyncratic dialects and error analysis. International Review of Applied Linguistics in Language Teaching, 9(2), 147-160. https://doi.org/10.1515/iral.1971.9.2.147

Dulay, H., Burt, M., \& Krashen, S. (1982). Language two. New York: Oxford University Press. 
Ferris, D. R., Liu, H., Sinha, A., \& Senna, M. (2013). Written corrective feedback for individual L2 writers. Journal of Second Language Writing, 22(3), 307-329. https://doi.org/10.1016/j. jslw.2012.09.009

Granger, S. (2003). The international corpus of learner English: A new resource for foreign language learning and teaching and second language acquisition research. TESOL Quarterly, 37(3), 538-546. https://doi.org/10.2307/3588404

James, C. (1998). Errors in language learning and use: Exploring error analysis. Harlow, UK: Longman. Levelt, W. J. M. (1978). Skill theory and language teaching. Studies in Second Language Acquisition, 1(1), 53-70. https://doi.org/10.1017/S0272263100000711

McDowell, L. (2016). An Error Analysis of Japanese scientists' research articles. (Master of Research). Macquarie University, Sydney, Australia. Retrieved from https://www.researchonline.mq.edu.au/ vital/access/services/Download/mq:57812/SOURCE1?view=true

McDowell, L., \& Liardét, C. L. (2019). Japanese materials scientists' experiences with English for research publication purposes. Journal of English for Academic Purposes, 37, 141-153. https://doi: 10.1016/j.jeap.2018.11.011

McDowell, L., \& Liardét, C. (2020). Towards specialized language support: An elaborated framework for Error Analysis. English for Specific Purposes, 57, 16-28. https://doi.org/10.1016/j. esp.2019.09.001

Richards, J. C. (1971). A non-contrastive approach to error analysis. English Language Teaching, 25, 204-219.

Richards, J. C. (1974). Error analysis: Perspectives on second language acquisition. London: Longman. Selinker, L. (1972). Interlanguage. International Review of Applied Linguistics in Language Teaching, 10, 209-231. https://doi.org/10.1515/iral.1972.10.1-4.209

Schachter, J., \& Celce-Murcia, M. (1977). Some reservations concerning error analysis. TESOL Quarterly, 11(4), 441-451. https://doi.org/10.2307/3585740

Wolfe-Quintero, K., Inagaki, S., \& Kim, H.Y. (1998). Second language development in writing: Measures of fluency, accuracy, \& complexity. Honolulu, HI: University of Hawaii Press. https://doi. org/10.1017/s0272263101263050

\section{Appendix}

Errors with Articles: Example Sentences

The sentences below, from the field of materials science, all include errors with articles (one error per sentence). Read these sentences and try to identify the noun groups with errors. For example, in the example sentence below, coupling partner needs an article or plural -s.
E.g., A dramatic enhancement in conversion was observed at around critical density when ethylene gas was employed as coupling partner.

After identifying the problematic noun group, use the flow-chart to revise the errors. For example, adding the indefinite article, as follows.

E.g., A dramatic enhancement in conversion was observed at around critical density when ethylene gas was employed as a coupling partner.

In the first three sentences, the noun group with error is already identified with an underline.

1. In $\mathrm{scCO}_{2}$ media, the solubility of substrate was enhanced generally around the pressure shown critical density owing to the clustering effect.

2. In the former paper ${ }^{12(c)}$, we reported a large deviation observed in the conversion, even after several washes, without reaction vessel decomposition.

3. For the purpose of clarity, Figures $1 \mathrm{c}, 1 \mathrm{~g}, 1 \mathrm{k}$, and $1 \mathrm{p}$ show the either one of the crystal structures.

4. Au electrode was used as a working electrode, while Pt wire and $\mathrm{Ag} / \mathrm{AgCl}(3 \mathrm{M} \mathrm{NaCl})$ were used as counter and reference electrodes, respectively.

5. In conclusion, we have demonstrated the correlation between the coordination geometry around the $\mathrm{Eu}^{\mathrm{III}}$ center and the luminescence dissymmetry factor using 20 varieties of the $\mathrm{Eu}^{\mathrm{III}}$ complexes.

6. Initially, the pristine SWNT film showed positive Seebeck coefficient $(+49 \mathrm{uV} / \mathrm{K})$, and conductivity of $36 \mathrm{~S} / \mathrm{cm}$.

7. $\mathrm{ScCO}_{2}$ is a unique media that forms the cluster owing to the density fluctuation around the critical point.

8. Similar energy shift derived from the n-type doping was predicted by theoretical calculations and experimentally observed for potassium-doped SWNTs.

\section{Answers}

1. In $\mathrm{scCO}_{2}$ media, the solubility of the substrate was enhanced generally around the pressure shown critical density owing to the clustering effect. (omission/definite article)

2. In the a former paper ${ }^{12(c)}$, we reported a large deviation observed in the conversion, even after several washes, without reaction vessel decomposition. (selection/ indefinite article) 
3. For the purpose of clarity, Figures $1 \mathrm{c}, 1 \mathrm{~g}, 1 \mathrm{k}$, and $1 \mathrm{p}$ show the either one of the crystal structures. (addition/definite article)

4. An Au electrode was used as a working electrode, while Pt wire and $\mathrm{Ag} / \mathrm{AgCl}(3$ $\mathrm{M} \mathrm{NaCl}$ ) were used as counter and reference electrodes, respectively. (omission/ indefinite article)

5. In conclusion, we have demonstrated the a correlation between the coordination geometry around the $\mathrm{Eu}^{\mathrm{III}}$ center and the luminescence dissymmetry factor using 20 varieties of the Eu ${ }^{\text {III }}$ complexes. (selection/indefinite article)

6. Initially, the pristine SWNT film showed a positive Seebeck coefficient $(+49 \mathrm{uV} / \mathrm{K})$ and conductivity of $36 \mathrm{~S} / \mathrm{cm}$. (omission/indefinite article)

7. $\mathrm{ScCO}_{2}$ is a unique media that forms the clusters owing to the density fluctuation around the critical point. (selection/indefinite plural)

8. A Ssimilar energy shift derived from the n-type doping was predicted by theoretical calculations ${ }^{[20]}$ and experimentally observed for potassium-doped SWNTs (omission/ indefinite article).
Flow-chart Guiding the Decisions that Need to be Made in the Appropriate Choice of Articles and Plural-s

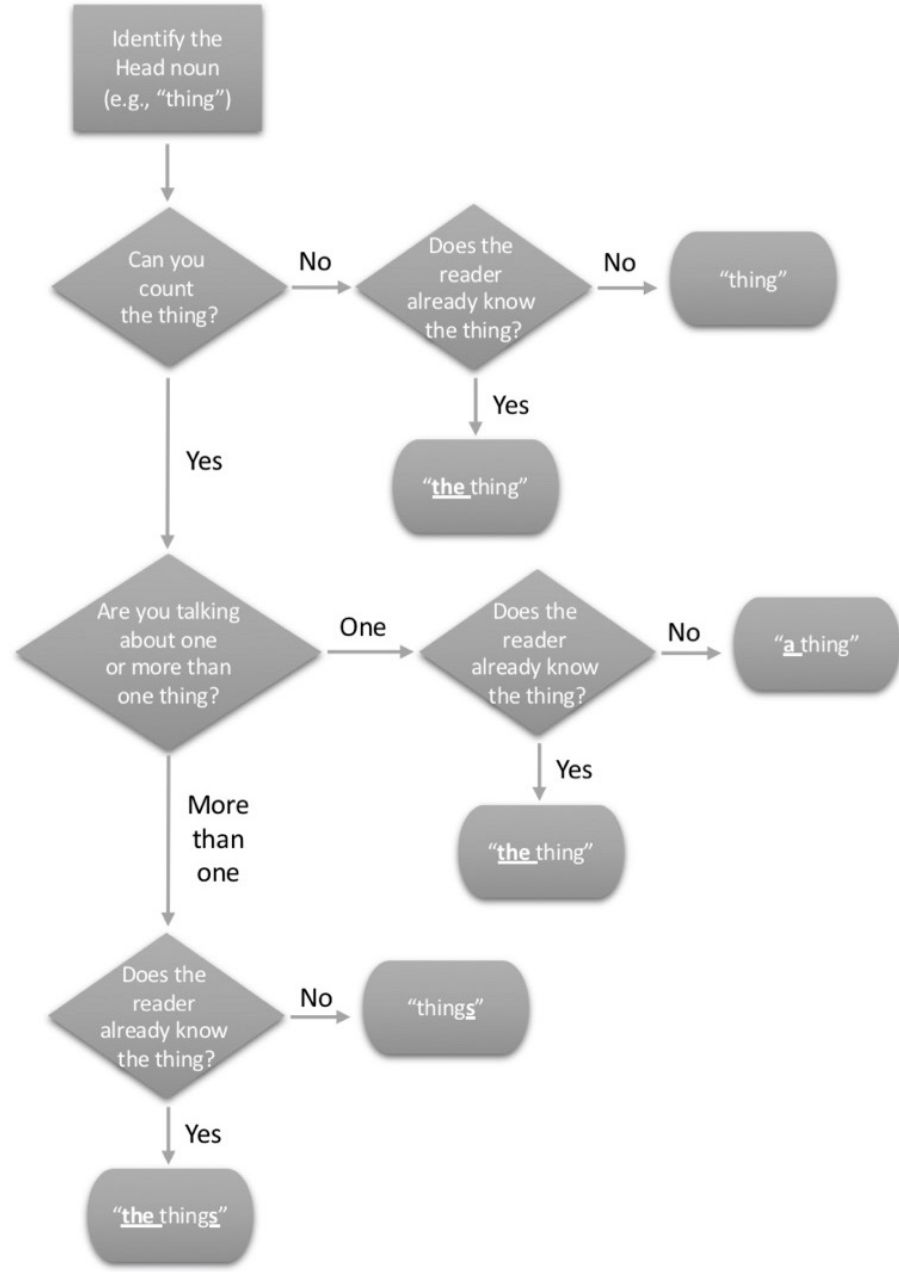

Additional exercises addressing errors with articles for materials science can be accessed from Research Gate with the following DOI: https://doi.org/10.13140/ RG.2.2.12034.02248. 